\title{
A case of Plasmodium malariae recurrence: recrudescence or reinfection?
}

\author{
Romualdo Grande ${ }^{1}$, Spinello Antinori ${ }^{2,3^{*}} \mathbb{0}$, Luca Meroni ${ }^{3}$, Michela Menegon ${ }^{4}$ and Carlo Severini ${ }^{4}$
}

\begin{abstract}
Background: Plasmodium malariae is the most neglected of the six human malaria species and it is still unknown which is the mechanism underlying the long latency of this Plasmodium.

Case presentation: A case of PCR-confirmed P. malariae recurrence in a 52-year old Italian man was observed 5 months after a primary attack. In the interval between the two observed episodes of malaria the patient denied any further stay in endemic areas except for a visit to Libya, a country considered malaria-free. Genomic DNA of the $P$. malariae strain using five microsatellites (PM2, PM9, PM11, PM25, PM34) and the antigen marker of circumsporozoite ( $c s p$ ) was amplified and sequenced. Analysis of polymorphisms of the P. malariae csp central repeat region showed differences between the strains responsible of the first and second episode of malaria. A difference in the allele size was also observed for the sequence analysis of PM2 microsatellites.
\end{abstract}

Conclusions: Plasmodium malariae is a challenging human malaria parasite and even with the use of molecular techniques the pathogenesis of recurrent episodes cannot be precisely explained.

Keywords: Plasmodium malariae, Malaria, Recrudescence, Long-latency

\section{Background}

Plasmodium malariae is the parasite responsible of quartan malaria with the typical periodicity of fever paroxysm observed every 72-h as detailed in a study by Camillo Golgi in 1886, but also described in the fourteenth Century by Dante Alighieri in the Divine Comedy (seventeen Canto of the Inferno) [1-3]. The parasite is widely distributed in most tropical and sub-tropical areas, with overlapping presence with Plasmodium falciparum, especially in sub-Saharan Africa, where it might easily be overlooked if molecular techniques such as polymerase chain reaction (PCR) are not used for diagnosis [1, 4]. Although it is well known that malaria episodes due to $P$. malariae can occur even after 30-50 years following a previous malaria attack, the mechanism responsible for its persistence and late recurrence still remains a medical mystery [5-8]. The failure to identify hypnozoites in liver biopsy of either human and animals is considered a proof that

\footnotetext{
*Correspondence: spinello.antinori@unimi.it

2 Department of Biomedical and Clinical Sciences "Luigi Sacco", University of Milan, Milan, Italy

Full list of author information is available at the end of the article
}

P. malariae is not a relapsing Plasmodium species, thus still giving the Bignami's interpretation of endo-erythrocytic persistence of the parasite as the more satisfactory $[3,8-10]$. However, the fact that the existence of $P$. malariae hypnozoites has never been proven is not "per se" a proof against it. For instance Plasmodium ovale is credited to produce hypnozoite although $P$. ovale hypnozoites have never been demonstrated biologically. Herein it is described a case of $P$. malariae infection in an Italian man occurring 5 months after a previous malaria episode despite the fact he had not travelled to a malaria-endemic region. A review of similar cases is also described together with possible explanation of this phenomenon.

\section{Case presentation}

A 52-year-old Italian man sought care at the Emergency Department (ED) of Luigi Sacco Hospital in Milan, Italy on 14 December, 2017, complaining of a quartan pattern of fever that started 1 week before together with arthralgia and myalgia. He reported frequent trips to sub-Saharan Africa, the last one to Mozambique and several previous malaria attacks treated by himself using quinine. He reported to have not taken anti-malarial 
chemoprophylaxis. A chest X-ray was negative and laboratory examinations were unremarkable except for an increase of $C$ reactive protein $(50.9 \mathrm{mg} / \mathrm{L})$ and mild thrombocytopaenia $(153,000 / \mu \mathrm{L})$. A blood smear was negative for malaria parasites as well as a rapid diagnostic test (RDT), but species-specific PCR turned positive for P. malariae. He was treated with a standard regimen of oral chloroquine phosphate $(1 \mathrm{~g}$ per os initially, $500 \mathrm{mg}$ $6 \mathrm{~h}$ after the first dose, and then $500 \mathrm{mg}$ once a day on the 2nd and 3rd days of therapy). Subsequently he was in good health until the end of April when fever recurred spiking to $40{ }^{\circ} \mathrm{C}$ associated with severe headache. On 4 May, 2018 he presented to the ED of another hospital where a blood smear was positive for trophozoites of Plasmodium spp. He was transferred to the ED of L. Sacco hospital where a new blood smear showed scanty trophozoites of $P$. malariae; RDT was negative and species-specific PCR confirmed the diagnosis of $P$. malariae. Clinical examination was remarkable for the presence of herpes labialis, but otherwise negative. A chest X-ray was negative and blood examinations showed increase C-reactive protein $(201 \mathrm{mg} / \mathrm{L})$ mild anaemia (Hb $12.2 \mathrm{~g} /$ dL, Ht 35\%), leukopaenia (WBC 3200/ $\mu \mathrm{L}$ ) and thrombocytopaenia $(45,000 / \mu \mathrm{L})$. In the period between the two $P$. malariae episodes he admitted only a short stay in northern Africa (Libya) without any other trip to sub-Saharan Africa. He was admitted to the Infectious Diseases Ward and treated with a 3-day course of dihydroartemisininpiperaquine (320/40 mg) 4 tablet/day for 3 days. He was discharged on 8 May, 2018 with negative blood smear and PCR for malaria. On follow-up he had normalization of blood examinations and up to January 2019 no more recurrences of malaria.

\section{Methods}

Plasmodium malariae genomic DNA was extracted from $200 \mu \mathrm{L}$ of whole infected blood samples collected from the patient at both hospital admittances, using PureLink Genomic DNA Kit-Invitrogen. Five microsatellites (MSs) (PM2, PM9, PM11, PM25, PM34) and the antigenic marker $P$. malariae circumsporozoite (Pmcsp) gene were genotyped, by PCR amplification and sequencing, in $P$. malariae isolate(s) responsible for the patient's infection in order to compare the primary infection and the second episode.

Microsatellite amplification was performed using specific primers previously described by Bruce et al. [11], adopting slight modifications in the amplification protocol (Table 1). For amplification of Pmcsp gene, two internal primers were designed specifically and used to amplify the central repeat region of the gene (Table 1). All PCR products were examined by gel electrophoresis and sent to Eurofins Genomics Company (Germany) for
Table 1 Primers and cycling parameters for PCR

\begin{tabular}{|c|c|c|}
\hline Primers & Aminoacids & $\begin{array}{l}\text { PCR cycling } \\
\text { parameters }\end{array}$ \\
\hline Pm09for & ACG ATA ATA ATA TAA ATG GGG & \multirow{6}{*}{$\begin{array}{l}94^{\circ} \mathrm{C}-30 \mathrm{~s} \\
45^{\circ} \mathrm{C}-30 \mathrm{~s} \\
72^{\circ} \mathrm{C}-1 \mathrm{~min}, 40 \\
\text { cycles }\end{array}$} \\
\hline Pm09rev & GTT CAT AAC TTT GAT CTT AAC & \\
\hline Pm11for & GGG ATA TGA ATT ACA TAC AC & \\
\hline Pm11rev & CTTTATTTG TGG TCG AGG & \\
\hline Pm25for & CCA AAT AAG TGA CAT ACA AC & \\
\hline Pm25rev & GAG GTA ACT TAA AAA ATT CAC & \\
\hline Pm02for & GGG GCA TAA AGG AAA AAC & \multirow{8}{*}{$\begin{array}{l}94^{\circ} \mathrm{C}-30 \mathrm{~s} \\
52^{\circ} \mathrm{C}-30 \mathrm{~s} \\
72^{\circ} \mathrm{C}-1 \mathrm{~min}, 40 \\
\text { cycles }\end{array}$} \\
\hline Pm02rev & GAA TTT TTG AAT AAC AAG AAA CC & \\
\hline Pm34for & GAA TGG AAA AAT TCC TTC AG & \\
\hline Pm34rev & TTG GAC AAT GAA AAA ACT AAG & \\
\hline Pm MSP1for & TTC CAA AAA TTG AGG AAA TGTT & \\
\hline Pm MSP1rev & TTT GGA CAA TGT CGG AAC AA & \\
\hline Pm CSfor & CCC ACA AAA GCT GTT GAA AA & \\
\hline Pm CSrev & TGG TGA CCA TTC CTC CGT A & \\
\hline
\end{tabular}

sequencing. The obtained sequences were compiled and analysed by Accelrys DS Gene Software.

Comparison of the genetic diversity of $P$. malariae isolates collected from the patient's two blood specimens collected on first hospital admission (14 December, 2017) and on second admission (5 May, 2018) was performed by direct sequencing of the amplified fragments of six $P$. malariae molecular markers.

A PubMed, Scopus and EMBASE literature search was performed from 1940 to 2018 with the search terms P. malariae AND "recrudescence" AND "recurrence" AND "relapse". Several cases were added by cross-referencing the articles cited in the retrieved case reports. Articles in Chinese, Russian and Japanese languages were excluded.

\section{Results}

In each of two tested DNA samples, a single amplified product was observed on agarose gel for each analysed target, suggesting the presence of a single detectable isolate for each malaria episode. The central region of Pmcsp gene and three MSs (PM2, PM9, PM34) were successfully sequenced in patient's two blood specimens. The result of the sequencing of PM11 and PM25 showed the amplification of non-specific bands, resulting in a cross-reaction with human DNA, and for this reason these two molecular markers were excluded by the present analysis.

Analysis of polymorphisms of the Pmcsp central repeat region resulted in the amplification of a DNA fragment of 864 base pairs (bps) (288 aminoacids) in the isolate responsible of the first episode, with a repeat region characterized by two NDAG tetrapeptide repeat units followed by 51 NAAG tetrapeptide repeat units. The isolate 
collected from the second episode had a more complex structure of the central repeat region $\left(\mathrm{NDAG}_{3}+\mathrm{NAAG}\right.$ $\left.{ }_{1}+\mathrm{NAAG}_{5}+\mathrm{NDAG}_{1}+\mathrm{NAAG}_{9}+\mathrm{NDAG}_{1}+\mathrm{NAAG}_{20}\right)$ for a total length of 816 bps (272 aminoacids) (Fig. 1; Additional file 1: Figure S1).

The sequence analysis of PM2 displayed two different size variants: $P$. malariae isolate collected in December's specimen had an allele size of 192 nucleotides (nts) due to a repeat unit region of $68 \mathrm{nts}$; instead, the second isolate collected in the second hospital admission showed an allele size of $216 \mathrm{nts}$ with a repeat region of $92 \mathrm{nts}$ (Fig. 2: Additional file 2: Figure S2). However, both P. malariae isolates collected from the patient displayed the same allele for PM9 (439 nts in size) and PM34 microsatellites (295 nts).

\section{Review}

Twenty-three case reports of $P$. malariae recrudescence were retrieved from the literature and are summarized in Table $2[5-7,12-31]$. However, it is plausible that very ancient case reports written in languages other than English were overlooked by this research by the fact that they are not included in modern databases. The oldest retrieved report about late $P$. malariae recrudescence was published by Shute in 1944 in The Lancet and the same author in a review regarding imported malaria in the UK cited another two observed cases occurring after 10 and 15 years [12, 32].

In the oldest cases recorded the diagnosis of $P$. malariae infection was based on microscopy only and the long latency before the recrudescence was inferred by the notion about elimination of malaria in the country of origin or by the last time in which the patients lived in or travelled to an endemic area [5, 6, 12-17, 19-21]. No difference of gender was observed in the cases reported in the literature and the median age of patients was 59 years. A quartan fever paroxysm was reported in $73.3 \%$ of described cases for whom this information was available (11/15) [6, 7, 13-15, 17-19, 26]. Malaria was acquired in Europe (before its elimination) in 7 cases, in sub-Saharan Africa in 11 cases, in Southeast Asia in 3 cases, and in Trinidad in the remaining case. The attack of malaria was precipitated by surgery in five patients (splenectomy in 3 cases), and immunosuppressive therapy in 2 patients $[5-7,15,17,19,21]$. An episode of falciparum malaria preceded the recrudescence by $P$. malariae in 4 patients consistent with the possibility of initially overlooked mixed infections $[18,22,23$, 25]. Six patients had a documented episode of malariae malaria 4 weeks to 25 months before the diagnosis of recrudescence [26-31]. Splenomegaly was documented in 9 patients (36.4\%) and in two cases splenectomy was

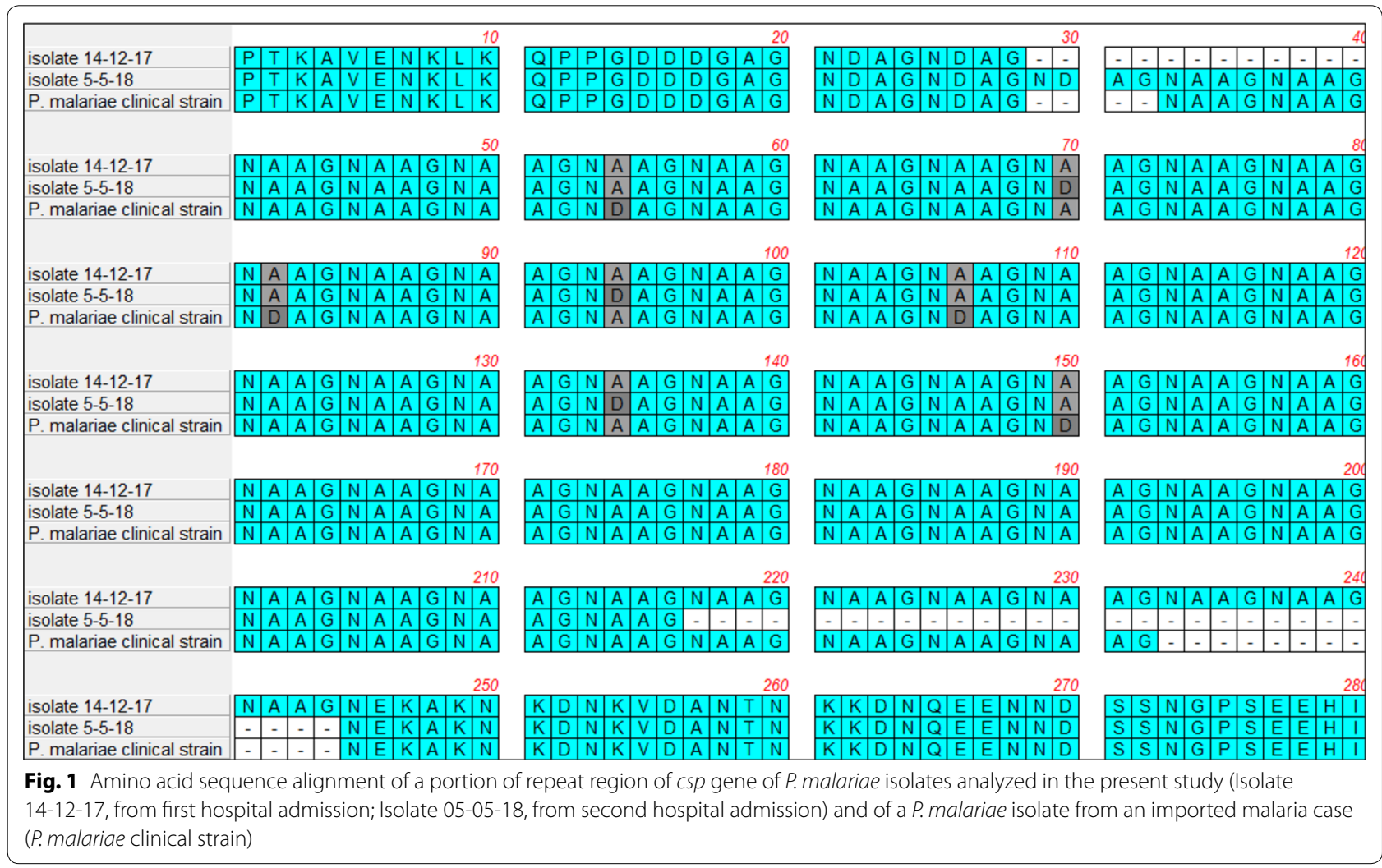




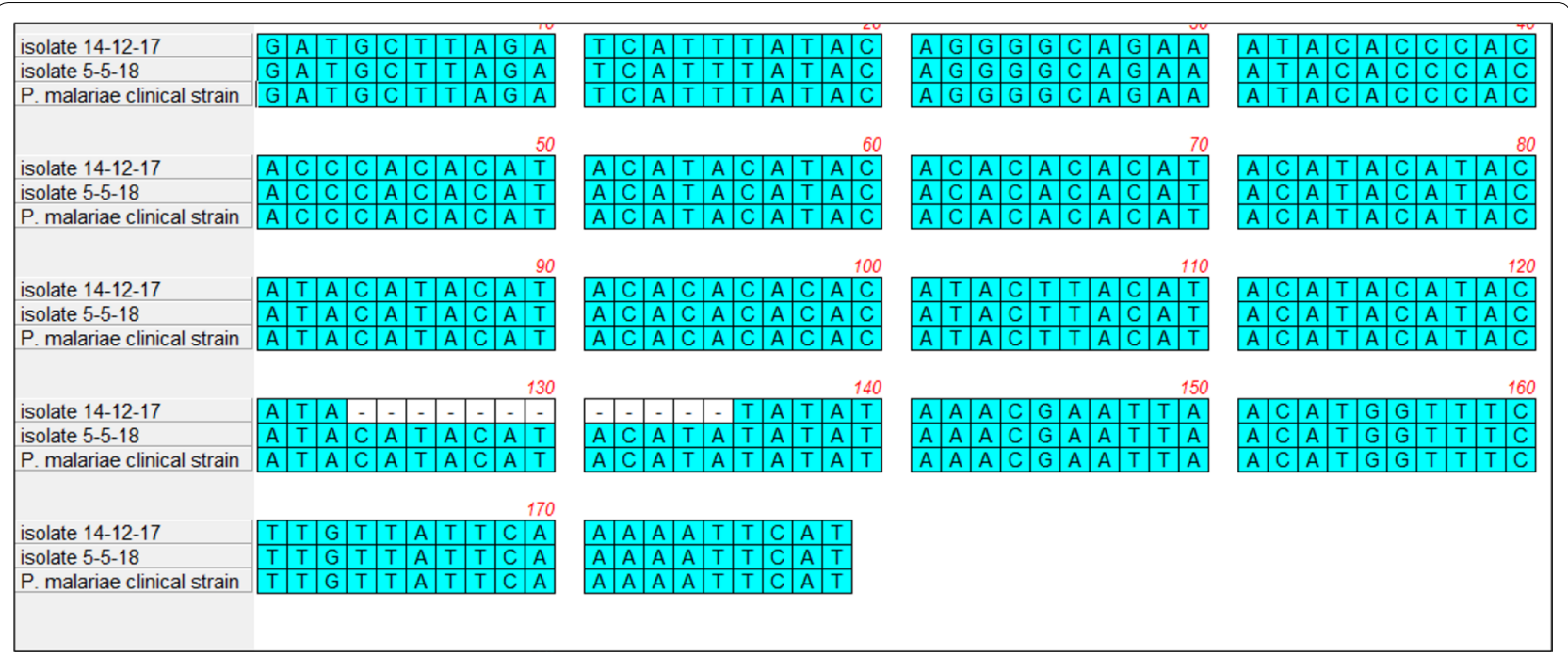

Fig. 2 Nucleotide sequence alignment of PM2 microsatellite of P. malariae isolates analyzed in the present study (Isolate PM 14-12-17, from first hospital admission; Isolate PM 05-05-18, from second hospital admission) and of a P. malariae isolate from an imported malaria case (P. malariae clinical strain)

undertaken as diagnostic evaluation $[5,6,14,18-21$, $31]$. At the time of $P$. malariae recrudescence diagnosis, a nephritic syndrome was observed in two patients [21, 24]. Chloroquine was the drug most frequently employed for treatment (12 patients, $52.2 \%)$ followed by quinine ( 4 patients) $[6,7,13-15,19-21,23,25-31]$.

\section{Discussion}

Plasmodium malariae is the most neglected among Plasmodium species responsible of human malaria, being frequently undetected due to the very low parasitaemia it causes. Only recently a draft nuclear genome and a highquality reference genome of $P$. malariae have been made available but nevertheless this Plasmodium remains the most mysterious among human malaria parasites and its long-term persistence has so far been elusive to any convincing explanation [33, 34]. Moreover, the existence among African apes and New World monkeys of two very similar species based on morphologic characteristics (i.e., Plasmodium rhodaini and Plasmodium brasilianum) has raised the question whether $P$. malariae should be considered a zoonosis, an anthroponosis or as inferred by Lalremruata et al., at least in South America, $P$. malariae and $P$. brasilianum are a single anthropozoonotic species [35-37].

Recurrences of $P$. malariae infection even after more than 50 years of latency have been described in old malaria literature (Table 2) but the availability of molecular biology techniques nowadays allowed a better classification of such episodes as a consequence of recrudescence or re-infection [5-7, 12-31].

Herein it is described a case of an Italian man who presented two symptomatic PCR-confirmed episodes of $P$. malariae infection occurring 5 months apart. His medical history was notable for several previous episodes of malaria acquired during his frequent travels to sub-Saharan Africa, usually with self-treatment with quinine. In the interval between the two observed episodes of malaria the patient denied any further stay in endemic areas except for a visit to Libya, a country considered malaria-free, thus giving the hypothesis of a recrudescence as the most plausible. Interestingly, genotyping of four $P$. malariae specific genetic markers indicated substantial genetic diversity of the two $P$. malariae strains responsible for the first and the second malaria episode. In this context the possibility of a de-novo infection acquired in Libya cannot be discarded and the recent description in Italy by Martelli et al. [38] of two Malian immigrants diagnosed with falciparum malaria in Italy after a long stay ( 3 to 5 years) in Libya might be concordant with this hypothesis.

Alternatively, in the case of recrudescence, one can consider the possibility of chloroquine-resistance or inadequate drug concentration. To the best of knowledge clinical chloroquine-resistant $P$. malariae has been reported only in a study conducted in Indonesia and in a single anecdotal case acquired in Africa [28, 39]. In the former study one patient had persistent parasitaemia on day 28 and two had persistent parasitaemia on day 8 . However, Collins and Jeffery retrospectively analysed the curve of clearance of $P$. malariae among neurosyphilis patients infected with $P$. malariae and subsequently treated with chloroquine and showed that an extended clearance time is frequent with this species, concluding that is not indicative of resistance to chloroquine [40]. 


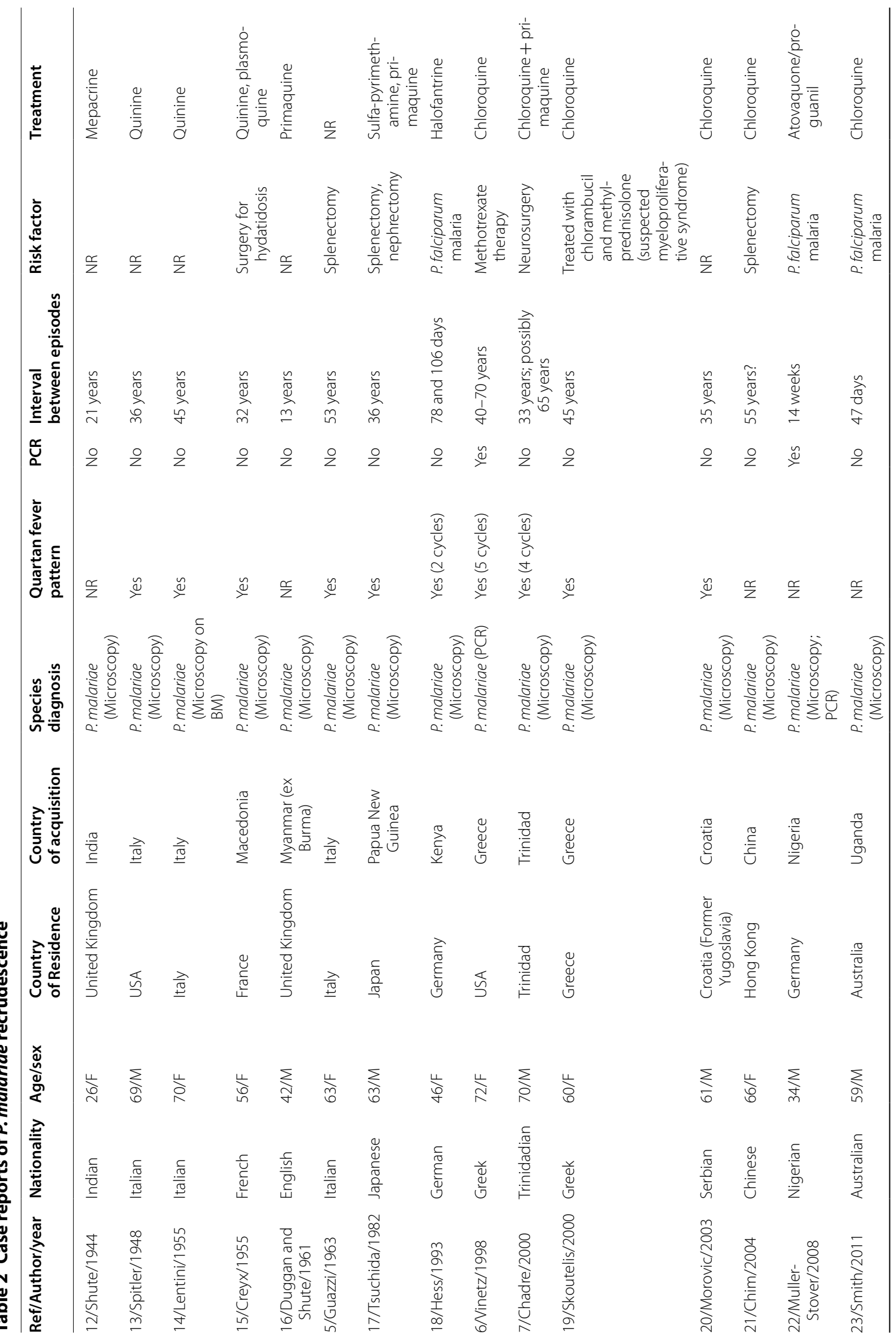




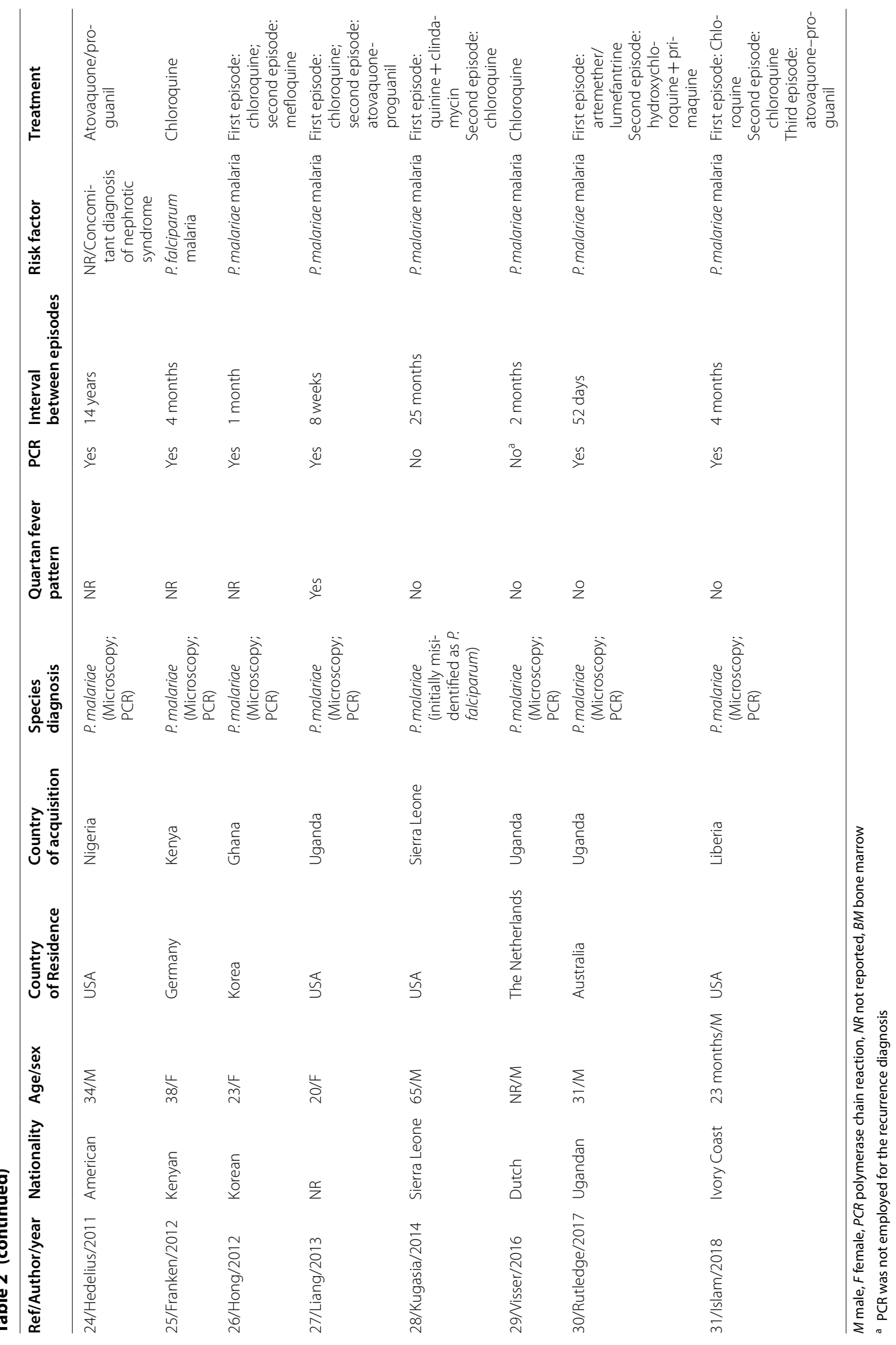


However, recurrence of $P$. malariae in cases of mixed malaria infections in which $P$. malariae was initially overlooked and the patients were treated for P. falciparum infection with mefloquine, halofantrine, quinine, or artemether/lumefantrine (AL) have been previously reported [18, 22, 23, 28]. More recently, Rutledge et al. [30] described a late recrudescence of $P$. malariae in which the minority initial subpopulation survived after treatment with AL and they postulated the need to use artemisinin combination therapy (ACT) with long half-life partner drug and longer follow-up of patients with $P$. malariae. Another possibility to be investigated as proposed for $P$. falciparum is the sequential use of two artemisininbased combination regimens [41]. As far as the described patient, although the malaria infection was acquired in Africa where a single possible $P$. malariae chloroquineresistant episode has been described, the decision was to treat the second episode of malaria with dihydroartemisinin-piperaquine (DHP) with no malaria recurrence after 8 months of follow-up [26]. However, given the long latency described for $P$. malariae infections it is presently unknown for how long a patient should be followed and, in clinical practice, among travellers with imported malaria follow-up longer than 4 weeks seems unfeasible [5-7, 12-17, 19-21, 23]. More recently, in a study aimed to investigate the biological basis of breakthrough $P$. malariae among travellers using atovaquone-proguanil chemoprophylaxis, Teo and co-workers showed the absence of mutation in the parasite locus pmcytb associated with recrudescence of $P$. falciparum [42]. These investigators hypothesized again the possibility that $P$. malariae is a relapsing parasite with the capacity to undergo latent hypnozoites in the liver responsible of new erythrocytic sexual replication years after the initial infection. Based on the life span of erythrocytes (110 days) and of hepatocytes (150300 days), Richter et al. [43] concurred with the hypothesis of the liver as the possible reservoir of $P$. malariae. However, Garnham, based on several observations concluded that "P. malariae are recrudescences of persisting blood forms of the respective parasites" [3, 8, 44].

Moreover, it is hard to explain how a dormant liver parasite is responsible of malaria transmitted by blood transfusion by an asymptomatic blood donor as long as 44 years after the last exposure in a malaria endemic area [45-47]. The interesting report by Rutledge and coworkers who showed that the recrudescent isolate in the patient they described was a single clone present at low density in the initial $P$. malariae infection, raised also the possibility that this patient harboured several different population of $P$. malariae acquired at different time frames with different fitness to anti-malarial drugs, one of which was capable of emerging when the susceptible ones were eliminated [30].
The review of the literature confirms the importance of immunity in controlling long-term latency of $P$. malariae with a state of balanced parasitism which can be abruptly broken by stress events, such as surgery or removing the spleen or by treatment with immunosuppressive drugs, each one responsible for recrudescence of malaria [5-7, $15,17,19,21]$. However, the precipitating event in several other cases remain unexplained [12-14, 16, 18, 20, 22-31]. Also intriguing is the ability of $P$. malariae to escape drugs which are blood schizontocidal for P. falciparum despite the very low parasitaemia that the former parasite produces. It can be speculated that in view of the long pre-patent period of $P$. malariae the duration of therapy against this Plasmodium should be increased and when using an artemisinin combination, as suggested by Rutledge et al., a partner drug that is slowly eliminated should be preferred [30,33].

\section{Conclusion}

It is described a case of probable $P$. malariae recrudescence, together with explaining hypothesis and a review of the literature of long-latency recrudescences. One-hundred and sixty-five years after its description $P$. malariae remains the most mysterious of the human malaria parasites and as suggested by Shute "it provides an almost perfect example of successful parasitism, without the frequent change of host need by other species of human malaria" [12]. Several recent thorough reviews about $P$. malariae persistent parasitism take again the hypnozoite hypothesis based on the fact that the "not proven existence" (as for $P$. ovale) should not be considered as proof for the non-existence of $P$. malariae hypnozoites and the need to search for an alternative place of dormancy, such as the spleen $[25,43,48-50]$.

\section{Additional files}

Additional file 1: Figure S1. Phylogenetic tree inferred from CSP nucleotide sequence alignment obtained from P. malariae isolates analyzed in the present study (Isolate PM 14-12-17; Isolate PM 05-05-17) and from 12 representative CSP gene sequences retrieved from the GenBank database. P. vivax CSP gene sequence (Genbank accession number AJ295636) was also included in the analysis and used as an outgroup. Phylogenetic analysis was done using the neighbour-joining method constructed using the neighbor-joining method by bootstrapping with 1000 replicates, and phylogenetic distances were measured by Tajima-Nei model, using the Accelrys DS Gene software package (Accelrys Inc., San Diego, CA, USA).

Additional file 2: Figure S2. Phylogenetic tree inferred from PM2 microsatellite sequence alignment obtained from P. malariae isolates analyzed in the present study (Isolate PM 14-12-17; Isolate PM 05-05-17) and from all representative sequences of PM2 microsatellite retrieved from the GenBank database. Phylogenetic analysis was done using the neighbourjoining method constructed using the neighbor-joining method by bootstrapping with 1000 replicates, and phylogenetic distances were measured by Tajima-Nei model, using the Accelrys DS Gene software package (Accelrys Inc., San Diego,CA,USA). Reference: Tajima F, Nei M. Estimation of evolutionary distance between nucleotide sequences. Mol Biol Evol. 1984;1:269-85. 


\section{Abbreviations}

PCR: polymerase chain reaction; ED: emergency department; RDT: rapid diagnostic test; MSs: microsatellites; csp: circumsporozoite; DHP: dihydroartemisinin-piperaquine; AL: artemether/lumefantrine; nts: nucleotides.

\section{Acknowledgements}

We would like to thank our librarian Virginia Zanzottera (Library Alberto Malliani, University of Milan) for help us to retrieve several old articles.

\section{Authors' contributions}

Study concept and design RG, SA, CS; care of the patient LM, SA; molecular biology analysis MM, CS; bibliography research: SA; drafting the manuscript SA, CS; critical comments on the manuscripts RG, LM, MM, CS; final approval of the version submitted RG, SA, LM, MM, CS. All authors read and approved the final manuscript.

\section{Funding}

This research did not receive any specific grant from funding agencies in the public, commercial, or not-for-profit sectors.

\section{Availability of data and materials}

The datasets used and/or analysed during the current study are available from the corresponding author on reasonable request.

\section{Ethics approval and consent to participate}

Written informed consent was obtained from the patient for publication of this case report anonymously. A copy of the written consent is available for review by the Editor-in-Chief of this Journal.

\section{Consent for publication}

Not applicable.

\section{Competing interests}

The authors declare that they have no competing of interests.

\section{Author details}

${ }^{1}$ Clinical Microbiology, Virology and Bioemergency, ASST Fatebenefratell Sacco, Luigi Sacco Hospital, Milan, Italy. ${ }^{2}$ Department of Biomedical and Clinical Sciences "Luigi Sacco", University of Milan, Milan, Italy. ${ }^{3}$ III Division of Infectious Diseases, ASST Fatebenefratelli Sacco, Luigi Sacco Hospital, Milan, Italy.

${ }^{4}$ Department of Infectious Diseases, Istituto Superiore di Sanità, Rome, Italy.

Received: 28 March 2019 Accepted: 7 May 2019

Published online: 14 May 2019

\section{References}

1. Collins WE, Jefferey GM. Plasmodium malariae: parasite and disease. Clin Microbiol Rev. 2007;20:579-92.

2. Golgi C. Malarial infection. Arch Sci Med. 1886;10:109-35 (in Italian)

3. Garnham PCC. The myth of quartan malaria (Haemamoeba laverani var. quartana Labbé, 1894). Trans R Soc Trop Med Hyg. 1981;75:616-7.

4. Betson M, Sousa-Figueiredo JC, Atuhaire A, Arinaitwe M, Adriko M, Mwesigwa G, et al. Detection of persistent Plasmodium spp. infections in Ugandan children after artemether-lumefantrine treatment. Parasitology. 2014:141:1880-90.

5. Guazzi M, Grazi S. Considerations on a case of quartan malaria recurring after 53 years of latency. Riv Malariol. 1963:42:55-9 (in Italian).

6. Vinetz JM, McCutchan TH, Kaslow DC. Plasmodium malariae infection in an asymptomatic 74-year-old Greek woman with splenomegaly. N Engl J Med. 1998:338:367-71.

7. Chadee DD, Tilluckharry CC, Maharai P, Sinanan C. Reactivation of Plasmodium malariae infection in a Trinidadian man after neurosurgery. N Engl J Med. 2000;342:1924.

8. Garnham PCC. The continuing mystery of relapses in malaria. Protozool Abstr. 1977;1:1-12.

9. Corradetti A, Verolini F. Relapses due to Plasmodium malariae and P. cynomolgi in infections produced by blood inoculations. Rend Ist Sup Sanit. 1951:14:271-81 (in Italian).
10. Bignami A. Sulla patogenesi delle recidive nelle febbri malariche. Atti Soc Studi Malaria. 1910;11:731-46.

11. Bruce MC, Macheso A, Galinski MR, Barnwell JW. Characterization and application of multiple genetic markers for Plasmodium malariae. Parasitology. 2007;134:637-50.

12. Shute PG. Relapse of quartan fever after 12 and 21 years. Lancet. 1944;2:146.

13. Spitler DK. Malaria relapse. Report of a case thirty-six years after original infection. N Engl J Med. 1948;238:839.

14. Lentini $D$, Tecce T. R Long-term recurrence of quartan malaria. Riv Malariol. 1955:34:259-65 (in Italian)

15. Creyx M, Leng-Levy J, Laborie G. Le problème des reviviscences tardives des paludismes humains. Presse Med. 1955;63:877-8.

16. Duggan AJ, Shute PG. Quartan malaria relapsing after thirteen years. J Trop Med Hyg. 1961;64:20-1.

17. Tsuchida H, Yamaguchi K, Yamamoto S, Ebisawa I. Quartan malaria following splenectomy 36 years after infection. Am J Trop Med Hyg. 1982;31:163-5

18. Hess FJ, Kilian HAD, Nothdurft HD, Loscher T. Problems in the therapy of mixed malarial infections: a case of infection with Plasmodium falciparum and P. malariae treated with mefloquine. Trans R Soc Trop Med Hyg. 1993;87:688.

19. Skoutelis A, Symeonidis A, Vassalou E, Bassaris H. Drug-induced acute malaria. Scand J Infect Dis. 2000;32:333.

20. Morovic M, Poljak I, Miletic B, Troselj-Vukic B, Seili-Bekafigo I, Milotic I. Late symptomatic Plasmodium malariae relapse in the territory of the former Yugoslavia. J Travel Med. 2003;10:301-2.

21. Chim CS, Wong SSY, Lam CCK, Chan KW. Concurrent hyperreactive malarial splenomegali and quartan malaria nephropathy-Plasmodium malariae revisited. Haematologica. 2004;89:e74-5.

22. Muller-Stover I, Verweij JJ, Hoppenheit B, Gubels K, Haussinger D, Richter J. Plasmodium malariae infection in spite of previous anti-malarial medication. Parasitol Res. 2008;102:547-50.

23. Smith A, Denholm J, Shortt J, Spelman D. Plasmodium species co-infection as a cause of treatment failure. Travel Med Infect Dis. 2011;9:306-9.

24. Hedelius R, Fletcher JJ, Glass WF II, Susanti AI, Maguire JD. Nephrotic syndrome and unrecognized Plasmodium malariae infection in a US Navy sailor 14 years after departing Nigeria. J Travel Med. 2011;18:288-91.

25. Franken G, Müller-Stöver I, Holtfreter MC, Walter S, Melhorn H, Labisch A, et al. Why do Plasmodium malariae infections sometimes occur in spite of previous antimalarial medication? Parasitol Res. 2012;111:943-6.

26. Hong YJ, Yang SY, Lee K, Kim TS, Kim HB, Park KU, et al. A case of imported Plasmodium malariae malaria. Ann Lab Med. 2012;32:229-33.

27. Liang SY, Westblade LF, Mehrtens J, Burnham C-AD, KuhImann FM. Fever in a 20-year-old returned traveller. Clin Infect Dis. 2013;56:423.

28. Kugasia IR, Polara FK, Assallum H. Recrudescence of Plasmodium malariae after quinine. Case Rep Med. 2014:2014:590265.

29. Visser R, de Mast Q, Munnix I, van der Ven A, Dofferhoff T. Failure of atovaquone-proguanil chemoprophylaxis and chloroquine treatment in Plasmodium malariae infection. Travel Med Infect Dis. 2016;14:644-5.

30. Rutledge GG, Marr I, Lin Huang GK, Auburn S, Marfurt J, Sanders M, et al. Genomic characterization of recrudescent Plasmodium malariae after treatment with artemether/lumefantrine. Emerg Infect Dis. 2017;23:1300-7.

31. Islam S, Hai F. Recrudescing Plasmodium malariae infection despite appropriate treatment in an immigrant toddler. Paediatr Int Child Health. 2018;38:290-3.

32. Shute PG, Maryon M. Imported malaria in the United Kingdom. BMJ. 1969:2:781-5.

33. Anasari HR, Templeton TJ, Subudhi AK, Ramaprasad A, Tang J, Lu F, et al. Genome-scale comparison of expanded gene families in Plasmodium ovale wallikeri and Plasmodium ovale curtisi with Plasmodium malariae and with other Plasmodium species. Int J Parasitol. 2016;46:685-96.

34. Rutledge GG, Böhme U, Sanders M, Reid AJ, Cotton JA, Maiga-Ascofare $\mathrm{O}$, et al. Plasmodium malariae and $P$. ovale genomes provide insights into malaria parasite evolution. Nature. 2017:542:101-4

35. Tazi L, Ayala FJ. Unresolved direction of host transfer of Plasmodium vivax v. Plasmodium simium and P. malariae v P. brasilianum. Infect Genet Evol. 2011;11:209-21.

36. Lalremruata A, Magris M, Vivas-Martinez S, Koehler M, Esen M, Kempaiah $P$, et al. Natural infection of Plasmodium brasilianum in humans: man 
and monkey share quartan malaria parasites in the Venezuelan Amazon. EBioMedicine. 2015;2:1186-92.

37. Rayner JC. Plasmodium malariae malaria: from monkey to man? EBioMedicine. 2015;2:1023-4.

38. Martelli G, Girometti N, Vanino E, Bottieau E, Viale P. Plasmodium falciparum malaria in migrants who transited Libya-Where did they contract malaria? Travel Med Infect Dis. 2015:13:499-500.

39. Maguire JD, Sumawinata IW, Masbar S, Laksana B, Prodjodipuro P, Susanti I, et al. Chloroquine-resistant Plasmodium malariae in south Sumatra, Indonesia. Lancet. 2002;360:58-60.

40. Collins WE, Jeffery GM. Extended clearance time after treatment of infections with Plasmodium malariae may not be indicative of resistance to chloroquine. Am J Trop Med Hyg. 2002;67:406-10.

41. Schallig HDFH, Tinto H, Sawa P, Kaur H, Duparc S, Ishengoma DS, et al. Randomised controlled trial of two sequential artemisinin-based combination therapy regimens to treat uncomplicated falciparum malaria in African children: a protocol to investigate safety, efficacy and adherence. BMJ Glob Health. 2017:2:e000371.

42. Teo BH, Landsell P, Smith V, Blaze M, Nolder D, Beshir KB, et al. Delayed onset of symptoms and atovaquone-proguanil chemoprophylaxis breakthrough by Plasmodium malariae in the absence of mutation at codon 268 of pmcytb. PLoS Negl Trop Dis. 2015;9:e0004068.

43. Richter J, Franken G, Holtfreter MC, Walter S, Labisch A, Mehlhorn H. Clinical implications of a gradual dormancy concept in malaria. Parasitol Res. 2016;115:2139-48.
44. Garnham PCC. Malaria parasites of man: life-cycles and morphology (excluding ultrastructure). In: Wernsdorfer WH, McGregor I, editors. Malaria-principles and practice of malariology. Edinburgh: Churchill Livingstone; 1988. p. 61-96.

45. Kitchen AD, Barbara JAJ, Hewit PE. Documented cases of post-transfusion malaria occurring in England. A review in relation to current and proposed donor-selection guidelines. Vox Sang. 2005;89:77-80.

46. Brouwer EE, van Hellemond JJ, van Genderen PJJ, et al. A case report of transfusion-transmitted Plasmodium malariae from an asymptomatic non-immune traveller. Malar J. 2013;12:439.

47. Tiburskaja NA, Vrubleskaja OS. Clinical and experimental studies on quartan malaria following blood transfusion and methods for preventing its occurrence. Bull World Health Organ. 1965;33:843-51.

48. Markus MB. Dormancy in mammalian malaria. Trends Parasitol. 2012;28:39-45.

49. Sutherland CJ. Persistent parasitism: the adaptive biology of malariae and ovale malaria. Trends Parasitol. 2016;32:808-19.

50. Markus MB. New evidence for hynozoite-independent Plasmodium vivax malarial recurrences. Trends Parasitol. 2018;34:1015-6.

\section{Publisher's Note}

Springer Nature remains neutral with regard to jurisdictional claims in published maps and institutional affiliations.
Ready to submit your research? Choose BMC and benefit from:

- fast, convenient online submission

- thorough peer review by experienced researchers in your field

- rapid publication on acceptance

- support for research data, including large and complex data types

- gold Open Access which fosters wider collaboration and increased citations

- maximum visibility for your research: over $100 \mathrm{M}$ website views per year

At BMC, research is always in progress.

Learn more biomedcentral.com/submissions 